\title{
Optimization of $\mathrm{Al} / \mathrm{AlO} \times \mathrm{X} / \mathrm{Al}$-layer systems for Josephson junctions from a microstructure point of view
}

Cite as: J. Appl. Phys. 125, 165301 (2019); https://doi.org/10.1063/1.5089871

Submitted: 23 January 2019 . Accepted: 04 April 2019 . Published Online: 22 April 2019

S. Fritz, L. Radtke, R. Schneider, M. Weides (D), and D. Gerthsen
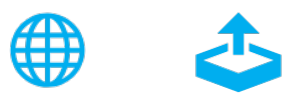

View Online

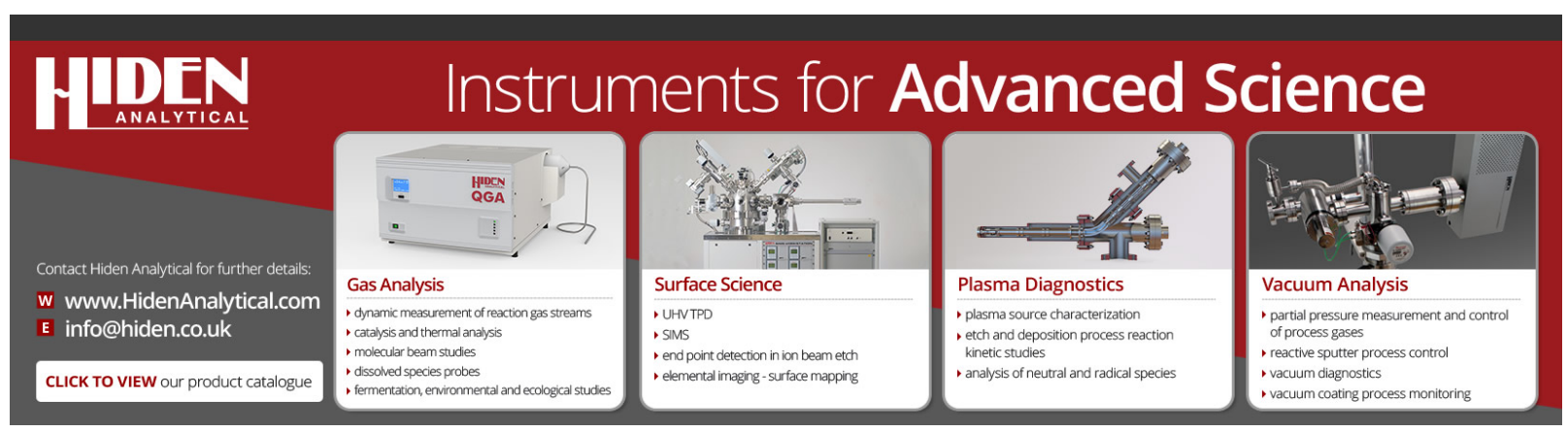




\title{
Optimization of $\mathrm{Al} / \mathrm{AlO}_{\mathrm{x}} / \mathrm{Al}$-layer systems for Josephson junctions from a microstructure point of view
}

\author{
Cite as: J. Appl. Phys. 125, 165301 (2019); doi: 10.1063/1.5089871 \\ Submitted: 23 January 2019 - Accepted: 4 April 2019 . \\ Published Online: 22 April 2019
}

S. Fritz, ${ }^{1, a)}$ L. Radtke, $^{2}$ R. Schneider, ${ }^{7}$ M. Weides, ${ }^{2,3}$ (iD and D. Gerthsen ${ }^{1, \text { a) }}$

\author{
AFFILIATIONS \\ ${ }^{1}$ Laboratory for Electron Microscopy, Karlsruhe Institute of Technology (KIT), 76131 Karlsruhe, Germany \\ ${ }^{2}$ Physikalisches Institut, Karlsruhe Institute of Technology (KIT), 76131 Karlsruhe, Germany \\ ${ }^{3}$ School of Engineering, University of Glasgow, G12 8LT Glasgow, United Kingdom
}

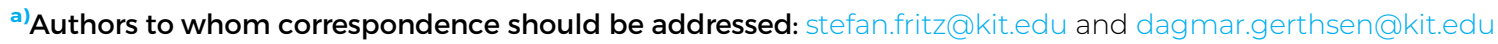

\begin{abstract}
$\mathrm{Al} / \mathrm{AlO}_{\mathrm{x}} / \mathrm{Al}$-layer systems are frequently used for Josephson junction-based superconducting devices. Although much work has been devoted to the optimization of the superconducting properties of these devices, systematic studies on the influence of deposition conditions, combined with structural analyses on the nanoscale, are rare up to now. We have focused on the optimization of the structural properties of $\mathrm{Al} / \mathrm{AlO}_{\mathrm{x}} / \mathrm{Al}$-layer systems deposited on $\mathrm{Si}(111)$ substrates with a particular focus on the thickness homogeneity of the $\mathrm{AlO}_{\mathrm{x}}$-tunnel barrier. A standard high-vacuum electron-beam deposition system was used, and the effect of substrate pretreatment, different Al-deposition temperatures, and Al-deposition rates was studied. Transmission electron microscopy was applied to analyze the structural properties of the $\mathrm{Al} / \mathrm{AlO}_{\mathrm{x}} / \mathrm{Al}$-layer systems to determine the thickness homogeneity of the $\mathrm{AlO}_{\mathrm{x}}$ layer, grain-size distribution in the $\mathrm{Al}$ layers, $\mathrm{Al}$-grain boundary types, and the morphology of the $\mathrm{Al} / \mathrm{AlO}_{\mathrm{x}}$ interface. We show that the structural properties of the lower $\mathrm{Al}$ layer are decisive for the structural quality of the whole $\mathrm{Al} / \mathrm{AlO}_{\mathrm{x}} / \mathrm{Al}$-layer system. Optimum conditions yield an epitaxial $\mathrm{Al}(111)$ layer on a $\mathrm{Si}(111)$ substrate with an Al-layer thickness variation of only $\pm 1.6 \mathrm{~nm}$ over more than $10 \mu \mathrm{m}$ and large lateral grain sizes up to $1 \mu \mathrm{m}$. Thickness fluctuations of the $\mathrm{AlO}_{\mathrm{x}}$-tunnel barrier are minimized on such an $\mathrm{Al}$ layer, which is essential for the homogeneity of the tunnel current. Systematic variation of the Al-deposition rate and deposition temperature allows one to develop an understanding of the growth mechanisms.
\end{abstract}

\section{Published under license by AIP Publishing. https://doi.org/10.1063/1.5089871}

\section{INTRODUCTION}

Superconducting devices are frequently based on Josephson junctions (JJ) fabricated on the basis of $\mathrm{Al} / \mathrm{AlO}_{\mathrm{x}} / \mathrm{Al}$-layer systems where a thin $\mathrm{AlO}_{\mathrm{x}}$ layer serves as a tunnel barrier. JJs are used, e.g., in superconducting quantum bits for the realization of quantum information circuits, ${ }^{1}$ single photon detectors, ${ }^{2}$ radiation detectors, ${ }^{3}$ single electron transistors, ${ }^{4}$ and superconducting quantum interference devices in magnetometers. ${ }^{5,6}$ The structural properties of the layer system have a profound influence on the performance of superconducting devices and on noise that limits detection sensitivity and coherence. For example, thickness variations of the $\mathrm{AlO}_{\mathrm{x}}$-tunnel barrier are a critical problem because the tunnel current scales exponentially with tunnel barrier thickness. The homogeneity of JJs is particularly crucial for complex superconducting circuits for quantum information processing, which contain a large number of JJs. A previous study by Zeng et al. ${ }^{7}$ has in this context shown that less than $10 \%$ of the total $\mathrm{AlO}_{\mathrm{x}}$-tunnel barrier area in JJs is active in the tunneling process in their $\mathrm{Al} / \mathrm{AlO}_{\mathrm{x}} / \mathrm{Al}$-based JJs due to thickness variations of the amorphous $\mathrm{AlO}_{\mathrm{x}}$ layer. This is disadvantageous with respect to performance and necessitates optimization of the thickness homogeneity of the tunnel barrier. $\mathrm{AlO}_{\mathrm{x}}$-thickness variations are predominantly caused by grain boundary (GB) grooving in the lower Al-electrode layer as shown by Nik et al. ${ }^{8}$ and our group. ${ }^{9}$ Hence, microstructure and homogeneity of the lower $\mathrm{Al}$ layer determine to a large degree the properties of the whole $\mathrm{Al} / \mathrm{AlO}_{\mathrm{x}} / \mathrm{Al}$-layer system and have to be optimized to provide the best possible surface for the formation of an $\mathrm{AlO}_{\mathrm{x}}$-tunnel barrier with homogeneous thickness. In fact, an $\mathrm{Al}$ layer grown epitaxially on a suitable substrate with an atomically flat surface would be ideal. 
Epitaxial growth of $\mathrm{Al}$ on $\mathrm{Si}$ substrates has already been realized by ultrahigh vacuum (UHV)-based deposition techniques like molecular beam epitaxy $(\mathrm{MBE})^{10}$ or UHV evaporation. ${ }^{11,12}$ However, UHV deposition systems are elaborate to operate and, in general, not well suited for JJ fabrication because shadow evaporation techniques ${ }^{13,14}$ are difficult to implement. Up to now, highvacuum (HV) electron-beam deposition systems, such as the Plassys MEB 550S system, are mainly used for JJ fabrication. With Al-deposition parameters, which are typically applied for JJ fabrication in HV systems (deposition rates of $0.1-1.2 \mathrm{~nm} / \mathrm{s}$ and substrate temperatures between room temperature and $200^{\circ} \mathrm{C}$ ), ${ }^{5,7,15-19}$ epitaxial growth of $\mathrm{Al}$ was not reported up to now.

Nevertheless, previous work in UHV systems gives useful hints on prerequisites for optimizing $\mathrm{Al}$ deposition. Chemical substrate cleaning prior to $\mathrm{Al}$ deposition ${ }^{20,21}$ is the first step on the path to epitaxial $\mathrm{Al}$ growth. A clean $\mathrm{Si} / \mathrm{Al}$ interface also improves the electrical properties of the whole $\mathrm{JJ}^{22}$ and is, thus, not only beneficial for $\mathrm{Al}$ growth. $\mathrm{Al}(111)$ surfaces have the lowest surface energy in $\mathrm{Al}^{23}$ and are best suited for obtaining epitaxial $\mathrm{Al}$ layers with a homogeneous thickness. Even epitaxial growth of $\gamma-\mathrm{Al}_{2} \mathrm{O}_{3}(111)$ on $\mathrm{Al}(111)$ has been observed under UHV conditions in a MBE system ${ }^{24,25}$ because $\mathrm{AlO}_{\mathrm{x}}$ layers on $\mathrm{Al}(111)$ have the lowest calculated critical thickness above which crystalline $\gamma-\mathrm{Al}_{2} \mathrm{O}_{3}$ layers are thermodynamically preferred over amorphous $\mathrm{AlO}_{\mathrm{x}}$ layers. ${ }^{24}$ Despite the lattice mismatch of 25.5\% between $\mathrm{Al}$ and $\mathrm{Si}$, epitaxial growth of $\mathrm{Al}(111)$ can be best achieved on $\mathrm{Si}(111)$ substrates. ${ }^{26,27}$ Using $\mathrm{Si}(100)$ substrates, Al tends to grow in the [110] direction, ${ }^{28}$ which is unwanted for the oxidation process. ${ }^{24}$ Moreover, the low surface energy of $\mathrm{Al}(111)$ is promising for achieving $\mathrm{Al}$ layers with homogeneous thickness. We note that we will consider the growth of $\mathrm{Al}(111)$ parallel to $\mathrm{Si}(111)$ as epitaxial growth, although grains can be rotated around the [111]-growth direction and the layer will, therefore, not be single-crystalline.

In this work, the structural properties of $\mathrm{Al} / \mathrm{AlO}_{\mathrm{x}} / \mathrm{Al}$-layer systems deposited on $\mathrm{Si}(111)$ substrates were correlated with growth conditions. The structural properties were investigated in detail by transmission electron microscopy (TEM). Substrate pretreatment and substrate temperature during $\mathrm{Al}$ deposition and Al-deposition rate were systematically varied to optimize the structural quality of $\mathrm{Al} / \mathrm{AlO}_{\mathrm{x}} / \mathrm{Al}$-layer systems in a standard electron-beam deposition system (Plassys MEB 550S) with a base pressure in the HV range. In particular, $\mathrm{AlO}_{\mathrm{x}}$-tunnel barriers with homogeneous thickness were obtained by achieving epitaxial growth of the lower Al layer, which provides a road map to optimize JJ fabrication.

\section{EXPERIMENTAL TECHNIQUES}

$\mathrm{Al} / \mathrm{AlO}_{\mathrm{x}} / \mathrm{Al}$-layer systems were deposited on single-crystalline $\mathrm{Si}$ (111)-substrates in a MEB 550S (PLASSYS Bestek, Marolles-enHurepoix, FR) electron-beam physical vapor deposition system with a base pressure in the HV regime where a pressure of $5 \times 10^{-7} \mathrm{mbar}$ is archived after $1 \mathrm{~h}$ of pumping. Pure $\mathrm{N}_{2}$ is used for venting and purging the chamber. The system is equipped with a kaufman source, which generates an $\mathrm{Ar} / \mathrm{O}$-plasma ( $4 \mathrm{sccm} \mathrm{Ar}$ and $0.5 \mathrm{sccm} \mathrm{O}_{2}$ ) with an acceleration voltage of $200 \mathrm{~V}$ and an ion current of $10 \mathrm{~mA}$ for removing carbonaceous contamination from the substrate.

In the first step, the cleaning of the $\mathrm{Si}(111)$ substrates was optimized and the influence of different procedures was studied.
All substrates were chemically treated to remove the protective resist layer by dipping the substrates successively in NEP (N-ethyl-2-pyrrolidon), isopropyl alcohol, and deionized water. In some experiments, an additional HF-dip process was applied to remove the native silicon oxide $\left(\mathrm{SiO}_{\mathrm{x}}\right)$ which remains after the first chemical cleaning. In this process, the substrate is dipped in the buffered oxide etch BOE 7:1 (12.5\% $\mathrm{HF}$ and 87.5\% $\left.\mathrm{NH}_{4} \mathrm{~F}\right)$ (Microchemicals GmbH, Ulm, Germany) for $45 \mathrm{~s}$. During the HF-dip etching, the $\mathrm{SiO}_{\mathrm{x}}$ layer is completely removed and an atomically flat hydrogen-terminated surface is formed. ${ }^{29}$ The substrate is then rinsed with deionized water to remove the BOE 7:1 and stop the etching process. Transfer and insertion of the HF-cleaned substrate in the MEB 550S system have to be completed in less than $1 \mathrm{~min}$ to avoid reoxidation in air. The load lock is pumped to $10^{-6}$ mbar, and the molybdenum sample plate is heated by a resistance heating wire to $175^{\circ} \mathrm{C}$ to desorb residual moisture from the substrate. After $25 \mathrm{~min}$ at $175^{\circ} \mathrm{C}$, the substrate temperature is increased to $700^{\circ} \mathrm{C}$ for $20 \mathrm{~min}$ to thermally desorb hydrogen, fluorine, and residual oxide. ${ }^{20}$ According to McSkimming et al., ${ }^{26}$ during this treatment, the Si substrate forms a Si(111) $7 \times 7$ reconstructed surface that remains stable even at lower temperatures. We could not verify the $\operatorname{Si}(111) 7 \times 7$ surface reconstruction because a reflection high-energy electron diffraction system is not available in our deposition system, but values for Al-thickness variations for our epitaxially grown samples (cf. Table II) are in agreement with values reported by McSkimming et al. ${ }^{26}$ for $100 \mathrm{~nm}$ Al deposited on $\mathrm{Si}(111) 7 \times 7$ in their UHV system. Also, according to McSkimming, epitaxial Al films occur only on $\mathrm{Si}(111) 7 \times 7$ or $\operatorname{Si}(111) \sqrt{3} \times \sqrt{3}$ surfaces, whereas unreconstructed $\operatorname{Si}(111) 1 \times 1$ surfaces lead to polycrystalline layers.

The lower Al layer is deposited by electron-beam evaporation from a pure Al target. Five samples with HF-dip and hightemperature treatment were fabricated with $\mathrm{Al}$ deposition at different substrate temperatures $T_{s}$ between $100^{\circ} \mathrm{C}$ and $300^{\circ} \mathrm{C}$. This temperature range was chosen because it is relevant for forming $\mathrm{AlO}_{\mathrm{x}}$-tunnel barriers by oxidation of the $\mathrm{Al}$ surface and eventually even growing crystalline $\mathrm{AlO}_{\mathrm{x}}$ layers. ${ }^{24}$ The growth of the layer system at room temperature, although frequently applied, is not compatible with the high-temperature step to generate a $7 \times 7$ reconstructed $\mathrm{Si}(111)$ surface because cooling to room temperature requires several hours and substrate holder cooling is not available in our deposition system. Contamination will occur during cooling to room temperature, which prevents epitaxial $\mathrm{Al}$ growth.

Al-deposition rates $r$ at $T_{s}=100{ }^{\circ} \mathrm{C}$ were varied from $0.1 \mathrm{~nm} / \mathrm{s}$ to $1 \mathrm{~nm} / \mathrm{s}$ which are basically the limits of our deposition system. Substrate temperature and deposition rate have the strongest influence on the microstructure of the deposited layer and are used as sample denotations (cf. Table I). Temperatures were controlled by a resistance temperature sensor on the backside of the sample plate and deposition rates were controlled by a piezoelectric sensor. The $\mathrm{Al}$ deposition was terminated at $100 \mathrm{~nm}$ layer thickness.

In the next step, the $\mathrm{AlO}_{\mathrm{x}}$ layer is formed by static oxidation by flooding the deposition chamber with pure oxygen. Oxidation parameters like partial oxygen pressure, oxidation temperature, or oxidation time were varied and sometimes plasma- or UV-enhanced oxidation was applied which leads to different $\mathrm{AlO}_{\mathrm{x}}$ thicknesses and $\mathrm{O}$ contents. We emphasize that the study of the effect of the 
TABLE I. Deposition conditions for the lower Al layer with corresponding sample denotations.

\begin{tabular}{lcc}
\hline \hline Sample & Deposition temperature $\left({ }^{\circ} \mathrm{C}\right)$ & Deposition rate $(\mathrm{nm} / \mathrm{s})$ \\
\hline $\mathrm{Al}_{300 \_0.1}$ & 300 & 0.1 \\
$\mathrm{Al}_{200 \_0.1}$ & 200 & 0.1 \\
$\mathrm{Al}_{100 \_0.1}$ & 100 & 0.1 \\
$\mathrm{Al}_{100 \_0.5}$ & 100 & 0.5 \\
$\mathrm{Al}_{100 \_1.0}$ & 100 & 1.0 \\
\hline
\end{tabular}

oxidation conditions on the oxygen concentration in the $\mathrm{AlO}_{\mathrm{x}}$-tunnel barrier is complex and will be presented in a separate publication. However, the variation of oxidation conditions does not affect the growth of the lower $\mathrm{Al}$ layer and the morphology of the $\mathrm{Al}$ surface at the $\mathrm{Al} / \mathrm{AlO}_{\mathrm{x}}$ interface and can be neglected regarding conclusions about the $\mathrm{Al}$ growth of the lower $\mathrm{Al}$ layer. In this work, we solely focus on the thickness homogeneity of the $\mathrm{AlO}_{\mathrm{x}}$ layers. In the last step, the upper $\mathrm{Al}$ layer is deposited using the same deposition parameters as for the lower $\mathrm{Al}$ layer.

Cross-section specimens for TEM were prepared by conventional mechanical preparation techniques as described by Strecker et $a .^{30}$ using $\mathrm{Ar}^{+}$-ion milling with a Gatan 691 PIPS (Gatan Inc., Pleasanton, USA) as a final preparation step. TEM and scanning transmission electron microscopy (STEM) were performed with a FEI $\operatorname{Titan}^{3}$ 80-300 (Thermo Fisher Scientific, Waltham, USA) operated at $300 \mathrm{kV}$. The instrument is equipped with an aberration corrector in the imaging lens system. Structure analyses were performed by comparing two-dimensional (2D) Fourier-transform patterns of high-resolution (HR)TEM images with simulated diffraction patterns using the JEMS software. ${ }^{31}$ Bragg filtering is applied to visualize the behavior of selected lattice planes by selecting the corresponding reflections in the 2D Fourier-transform pattern with a digital aperture and subsequently performing an inverse $2 \mathrm{D}$ Fourier transformation.

The thickness of the $\mathrm{AlO}_{\mathrm{x}}$ layer was measured on the basis of HRTEM images by acquiring intensity line profiles with an integration width of $2 \mathrm{~nm}$ perpendicular to the $\mathrm{AlO}_{\mathrm{x}}$ layer. In such profiles, the lattice planes of crystalline Al layers, in contrast to the amorphous $\mathrm{AlO}_{\mathrm{x}}$, show clear intensity maxima, and the distance between the uppermost lattice plane of the lower $\mathrm{Al}$ layer and the lowermost lattice plane of the upper Al layer can be measured.

\section{EXPERIMENTAL RESULTS AND DISCUSSION}

The results of our study are presented in three subsections. Section III A describes the optimization of the $\mathrm{Si}(111)$ substrate pretreatment. Section III B focuses on the correlation of the deposition conditions (substrate temperature during $\mathrm{Al}$ deposition and $\mathrm{Al}$-deposition rate) and structural properties of the lower $\mathrm{Al}$ layer, which determine the structural quality of the whole $\mathrm{Al} / \mathrm{AlO}_{\mathrm{x}} / \mathrm{Al}$-layer system. The analysis of the thickness homogeneity of the $\mathrm{AlO}_{\mathrm{x}}$ layer and the properties of the upper $\mathrm{Al}$ layer are presented in Sec. III C.

\section{A. Pretreatment of the Si(111) substrate for optimization of the $\mathrm{Al} / \mathrm{Si}\left(\begin{array}{lll}1 & 1 & 1\end{array}\right)$ interface}

Figure 1 shows HRTEM images of $\mathrm{Al} / \mathrm{Si}(111)$ interfaces after different $\mathrm{Si}(111)$ surface treatments prior to the deposition of the lower Al layer. The protective resist layer was removed on all Si(111) substrates by a chemical cleaning procedure (cf. Sec. II). For the sample shown in Fig. 1(a), only plasma cleaning by the kaufman source in the deposition system was applied for further cleaning to remove remnant carbon contamination. After this process, the $\mathrm{Si}(111)$ substrate is still covered with a $3 \mathrm{~nm}$ thick native amorphous $\mathrm{SiO}_{\mathrm{x}}$ layer which obviously cannot be removed by plasma cleaning. Irrespective of the $3 \mathrm{~nm} \mathrm{SiO}$ layer, grain orientations in the deposited polycrystalline $\mathrm{Al}$ layer often do not deviate strongly from the [111] direction of the substrate as indicated in Fig. 1(a).

To fulfill the prerequisites for epitaxial $\mathrm{Al}$ growth, the $\mathrm{SiO}_{\mathrm{x}}$ layer must be completely removed and a $7 \times 7$ reconstructed $\mathrm{Si}(111)$ surface has to be prepared in the deposition system (see Sec. II). The success of the procedure is seen in the HRTEM image [Fig. 1(b)] which demonstrates the complete lack of an amorphous $\mathrm{SiO}_{\mathrm{x}}$ layer and perfect alignment of the $\mathrm{Al}(111)$ planes parallel to the $\mathrm{Si}(111)$ substrate suggesting epitaxial growth of $\mathrm{Al}$ on $\mathrm{Si}(111)$.



FIG. 1. HRTEM images of the $\mathrm{Al} / \mathrm{Si}(111)$ interface of $\mathrm{Al} / \mathrm{AlO}_{x} / \mathrm{Al}$-layer systems with different substrate pretreatments. Chemical cleaning of the substrate to remove the protective resist was applied to all samples with (a) additional plasma cleaning in the deposition system or (b) additional HF-dip and high-temperature annealing at $700^{\circ} \mathrm{C}$ for 20 min prior to Al deposition. (c) Magnified section of the Al(111)/Si(111) interface in (b) using Bragg filtering with the (110) Al and (110) Si planes. 
However, the $\mathrm{Al}$ layer does not grow as a single-crystalline layer, but forms $\mathrm{Al}$ grains, which can be rotated around the [111] direction or occasionally slightly tilted. In fact, grain size and grain orientation are strongly affected by the Al-deposition parameters and will be discussed in Sec. III B. The large lattice-parameter mismatch of $25.5 \%$ between $\mathrm{Si}$ and $\mathrm{Al}$ leads to the formation of dislocations at the $\mathrm{Si}(111) / \mathrm{Al}(111)$ interface by the insertion of additional Al-lattice planes at the interface as shown in the Bragg-filtered HRTEM image in Fig. 1(c).

We note that the $\mathrm{SiO}_{\mathrm{x}}$ layer could not be consistently removed by the HF-dip for all samples despite identical etching times. The etching rate of BOE 7:1 was measured to be about $1 \mathrm{~nm} / \mathrm{s}$ by a series of etching steps using $200 \mathrm{~nm}$ thick $\mathrm{SiO}_{2}$ layers and with different etching times. A $45 \mathrm{~s}$ HF-dip should, therefore, have removed the $\mathrm{SiO}_{\mathrm{x}}$ layer completely. Thus, the $\mathrm{Si}$ surface must have been reoxidized in some cases after the etching process by residual oxygen in the deposition system or even during transfer to the deposition system. Transfer time into the deposition chamber is, therefore, a critical parameter and should not exceed $1 \mathrm{~min}$. Overall, HF-dip and a high-temperature heating step at $700{ }^{\circ} \mathrm{C}$ provides the best $\mathrm{Si}(111) / \mathrm{Al}(111)$ interface that can be achieved in our HV deposition system.

\section{B. Dependence of the microstructure of the lower Al layer on deposition conditions}

To optimize the growth of the lower Al layer, five samples with different fabrication conditions regarding Al-deposition rate and substrate temperature were investigated. $\mathrm{Si}(111)$ substrates were subjected to a HF-dip and subsequent high-temperature treatment in all cases to obtain a clean and atomically flat $\mathrm{Al}(111) / \mathrm{Si}(111)$ interface [cf. Fig. 1(b)]. Al deposition was performed under conditions listed in Table I, i.e., at substrate temperatures between $300{ }^{\circ} \mathrm{C}$ and $100^{\circ} \mathrm{C}$ with the same deposition rate $(0.1 \mathrm{~nm} / \mathrm{s})$. Two further experiments were carried out at $T_{s}=100^{\circ} \mathrm{C}$ and increased deposition rates $(0.5 \mathrm{~nm} / \mathrm{s}$ and $1 \mathrm{~nm} / \mathrm{s})$.

The morphology of the lower Al layer is illustrated by overview cross-section bright-field STEM images of the complete $\mathrm{Al} / \mathrm{AlO}_{\mathrm{x}} / \mathrm{Al}$-layer systems in Fig. 2 with the $\mathrm{Si}$ substrate, lower $\mathrm{Al}$ layer, $\mathrm{AlO}_{\mathrm{x}}$-tunnel barrier, and upper $\mathrm{Al}$ layer. In the following, we focus on the properties of the lower $\mathrm{Al}$ layer which are decisive for the structural quality of the whole layer system. For $\mathrm{Al}_{300 \_0.1}$ [Fig. 2(a)], only large islands with varying lateral size and height are observed making such layers unsuitable for JJ fabrication. A continuous lower $\mathrm{Al}$ layer is formed at reduced $T_{s}$ for sample $\mathrm{Al}_{200 \_0.1}$. The homogeneity of the lower $\mathrm{Al}$ layer is further improved by reducing $T_{s}$ to $100{ }^{\circ} \mathrm{C}\left[\mathrm{Al}_{100 \_0.1}\right.$, Fig. $\left.2(\mathrm{c})\right]$ and increasing deposition rates [samples $\mathrm{Al}_{100 \_0.5}$ and $\mathrm{Al}_{100 \_1.0}$, Figs. 2(d) and 2(e)]. The homogenization of the structural properties is visualized by the homogenization of the thickness of the lower $\mathrm{Al}$ layer and the reduction of grain orientation variations, which can be recognized by different bright-field STEM intensities of grains related to Bragg-diffraction contrast. A homogeneous bright-field STEM intensity can be clearly recognized for samples $\mathrm{Al}_{100 \_0.5}$ and $\mathrm{Al}_{100 \_1.0}$ [Figs. 2(d) and 2(e)] in contrast to $\mathrm{Al}_{200 \_0.1}$ and $\mathrm{Al}_{100 \_0.1}$ [Figs. 2(b) and 2(c)] with a polycrystalline structure.

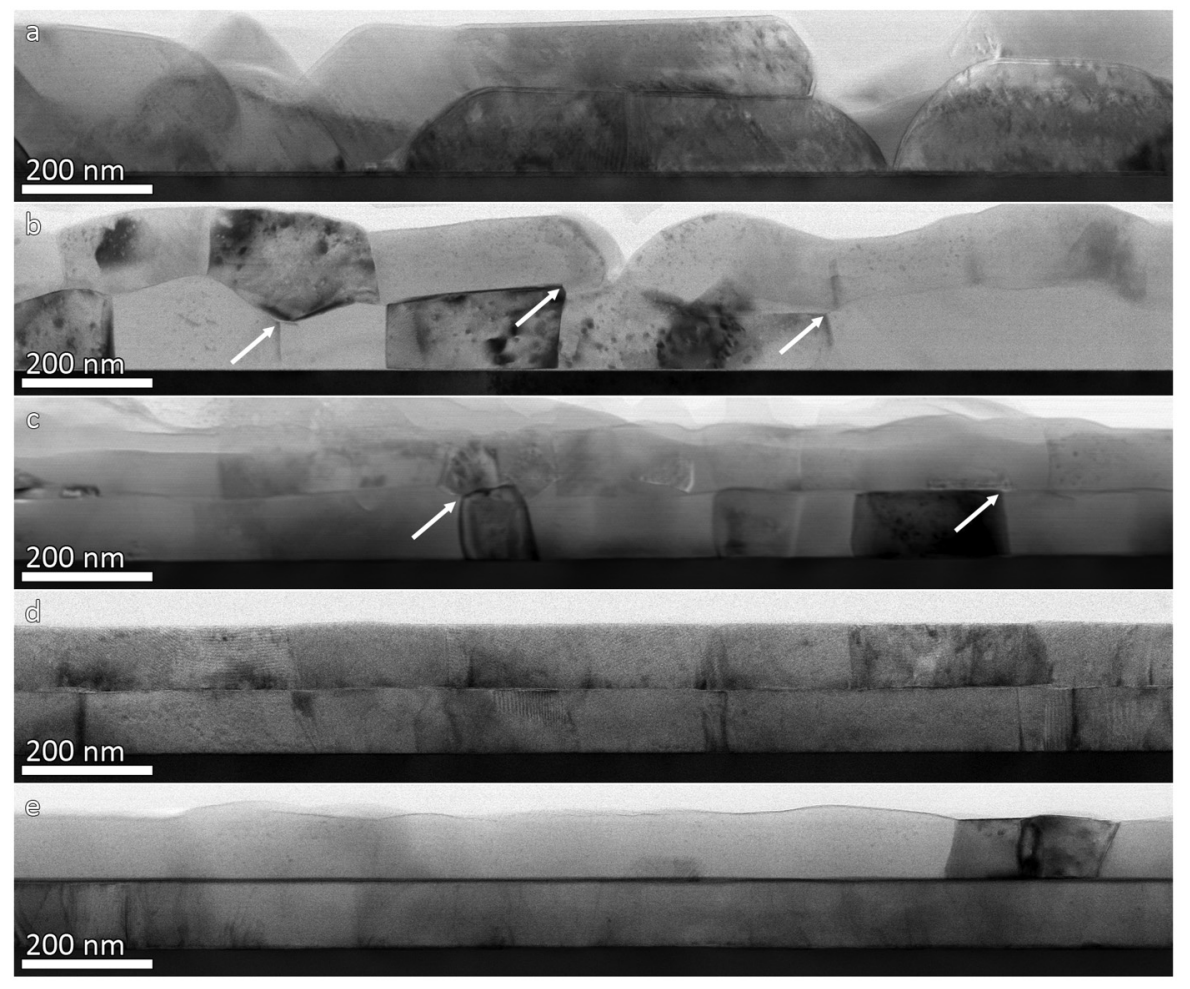

FIG. 2. Bright-field STEM images of Al/AIO $/$ Al-layer systems deposited at different substrate temperatures and Al-deposition rates on $\mathrm{Si}(111)$ substrates. (a) $\mathrm{Al}_{300 \_0.1}$, (b) $\mathrm{Al}_{200} 0.1$, (c) $\mathrm{Al}_{100} 0_{0.1}$, (d) $\mathrm{Al}_{100} 0.5$, and (e) $\mathrm{Al}_{100}{ }_{1.0}$. The white arrows mark grain boundaries with pronounced grain boundary grooving. 
TABLE II. Average lateral grain size, thickness of the lower Al layer, and thickness of the $\mathrm{AlO}_{\mathrm{x}}$ layer deposited at different temperatures and deposition rates.

\begin{tabular}{lccc}
\hline \hline Sample & $\begin{array}{c}\text { Average lateral } \\
\text { grain size }(\mathrm{nm})\end{array}$ & $\begin{array}{c}\text { Al-layer } \\
\text { thickness }(\mathrm{nm})\end{array}$ & $\begin{array}{c}\text { AlO }_{\mathrm{x}} \text {-layer } \\
\text { thickness (nm) }\end{array}$ \\
\hline $\mathrm{Al}_{300 \_0.1}$ & $375 \pm 116$ & $114.1 \pm 41.9$ & $1.62 \pm 0.29$ \\
$\mathrm{Al}_{200 \_0.1}$ & $244 \pm 87$ & $109.8 \pm 17.8$ & $1.65 \pm 0.23$ \\
$\mathrm{Al}_{100 \_0.1}$ & $200 \pm 71$ & $99.0 \pm 6.2$ & $1.73 \pm 0.19$ \\
$\mathrm{Al}_{100 \_0.5}$ & $269 \pm 107$ & $98.3 \pm 2.4$ & $1.59 \pm 0.11$ \\
$\mathrm{Al}_{100 \_1.0}$ & $347 \pm 208$ & $98.8 \pm 1.6$ & $4.88 \pm 0.17$ \\
\hline \hline
\end{tabular}

Measured lateral Al-grain sizes and Al-layer thicknesses illustrate the strong influence of $T_{s}$ and $r$ on the morphology of the lower $\mathrm{Al}$ layer. The roughness of $\mathrm{Al}$ layers is quantitatively determined by measuring grain thicknesses over lateral distances of $10-15 \mu \mathrm{m}$ with one data point every $50 \mathrm{~nm}$, which yields average values and standard deviations given in Table II. The samples show a wide range of thickness variations $\Delta t$ from $\pm 41.9 \mathrm{~nm}$ for $\mathrm{Al}_{300 \_0.1}$ due to island growth to the most homogeneous thickness for
$\mathrm{Al}_{100 \_1.0}$ with $\Delta t$ of only $\pm 1.6 \mathrm{~nm}$. There is an obvious trend toward more homogeneous Al-layer thickness with decreasing $T_{s}$ and increasing $r$. The reasons for this behavior are visible in Fig. 2. First, the grain surfaces flatten with decreasing $T_{s}$ and increasing $r$. The second effect that leads to thickness variations is grain boundary (GB) grooving which can also locally change the thickness of the $\mathrm{AlO}_{\mathrm{x}}$-tunnel barrier as discussed in detail by Nik et al. ${ }^{8}$ and Fritz et al. ${ }^{9}$ The growth experiments in this work show that GB grooving depends strongly on $T_{s}$ and $r$ as demonstrated by Fig. 2 where GB grooving is mainly observed in $\mathrm{Al}_{200 \_0.1}$ and $\mathrm{Al}_{100 \_0.1}$ [cf. arrows in Figs. 2(b) and 2(c)]. GB grooving is considerably reduced in $\mathrm{Al}_{100 \_0.5}$ [Fig. 2(d)] and almost completely suppressed in $\mathrm{Al}_{100 \_1.0}$ [Fig. 2(e)].

The distribution of lateral grain sizes is presented in Fig. 3 for all samples and average lateral grain sizes are given in Table II. The average grain sizes decrease for a constant deposition rate of $0.1 \mathrm{~nm} / \mathrm{s}$ with decreasing $T_{s}$. This trend is reversed if the deposition rate is increased for samples $\mathrm{Al}_{100 \_05}$ and $\mathrm{Al}_{100 \_1.0}$. The grain-size distribution can be well fitted by lognormal distributions for $\mathrm{Al}_{200 \_0.1}, \mathrm{Al}_{100 \_0.1}$, and $\mathrm{Al}_{100 \_0.5} \cdot \mathrm{Al}_{300 \_0.1}$ does not show such a distribution which can be attributed to a different growth mode by the

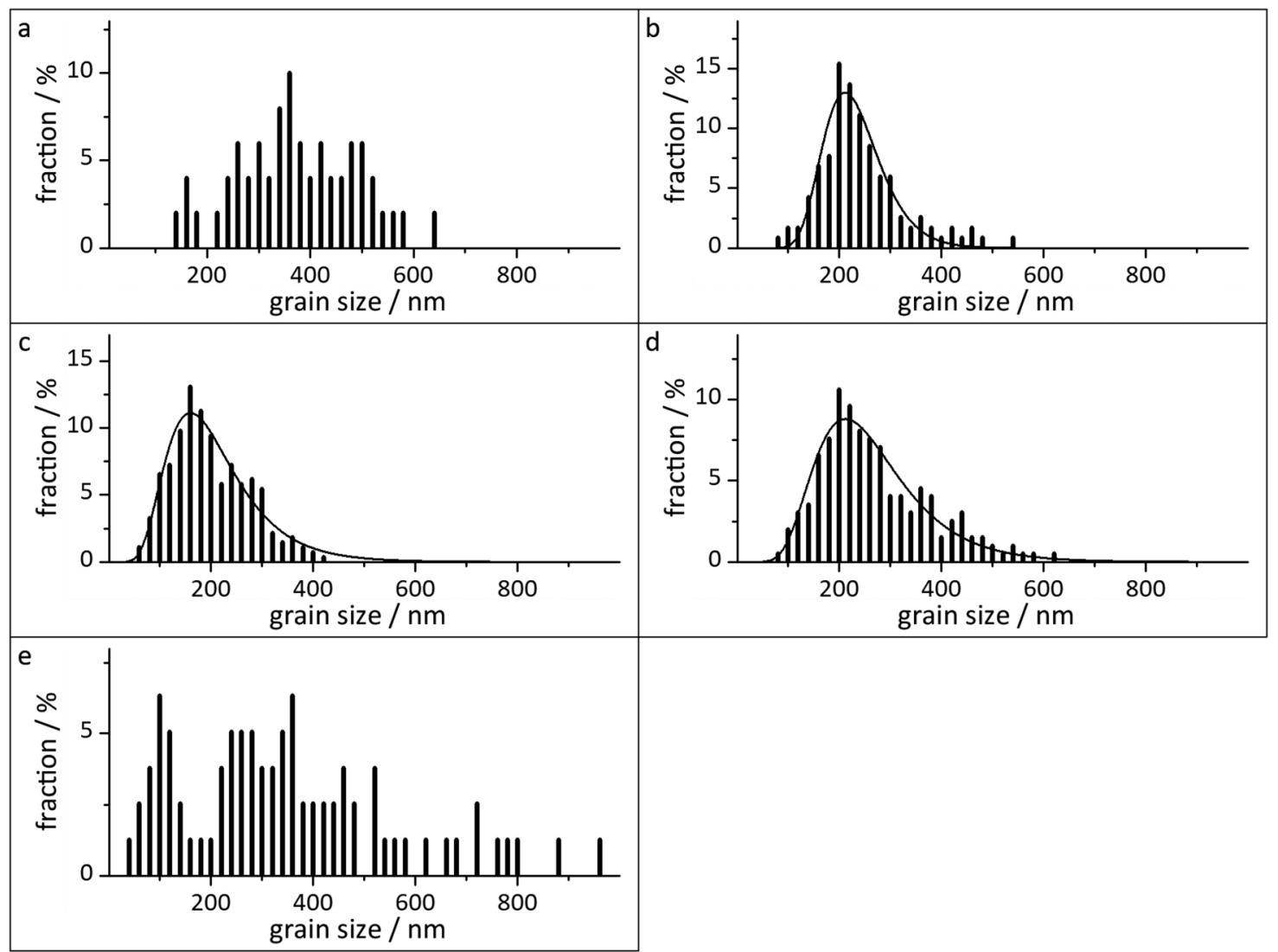

FIG. 3. Distribution of lateral grain sizes in the lower $\mathrm{Al}$ layer for samples deposited at different substrate temperatures and deposition rates on $\mathrm{Si}(111)$. (a) $A l_{300 \_0.1}$, (b) $\mathrm{Al}_{200 \_0.1}$, (c) $\mathrm{Al}_{100 \_0.1}$, (d) $\mathrm{Al}_{100 \_0.5}$, and (e) $\mathrm{Al}_{100 \_1.0}$ with fitted lognormal distributions (black line) in (b)-(d). 
formation of large islands instead of a continuous $\mathrm{Al}$ layer. Another exception is sample $\mathrm{Al}_{100 \_1.0}$ which shows a large number of small grains between $50 \mathrm{~nm}$ and $150 \mathrm{~nm}$ and a broad range of grain sizes with lateral extensions up to $1 \mu \mathrm{m}$.

The behavior of the average grain sizes and grain-size distributions can be understood by the following considerations. In the very initial deposition stage, $\mathrm{Al}$ islands are nucleated on the substrate, which coalesce at some point to a closed film. The size of the islands at the stage of coalescence decreases and the number density increases with decreasing deposition temperature because $\mathrm{Al}$-adatom mobility is reduced and the formation of large islands is prevented. After coalescence, grain coarsening occurs during further deposition to reduce the energy of the system that is stored in grain boundaries. Coarsening also depends on the grain boundary mobility which is temperature dependent, i.e., coarsening is less pronounced at lower temperatures and leads to smaller (average) grain sizes as observed for $\mathrm{Al}_{200 \_0.1}$ and $\mathrm{Al}_{100 \_0.1}$ (Table II). This coarsening behavior is denoted a normal grain growth ${ }^{32-34}$ and is characterized by a lognormal grain-size distribution which is found for all samples apart from samples $\mathrm{Al}_{300 \_0.1}$, where complete coalescence of islands was not yet achieved, and $\mathrm{Al}_{100 \_1.0}$ [cf. Figs. 3(a) and 3(e)]. The reduction of average grain size is reversed for the samples that were grown at $100^{\circ} \mathrm{C}$ with increased deposition rates. Higher deposition rates further impede Al-adatom mobility on the surface, i.e., the size of the islands at the stage of coalescence is further reduced. This increases the total grain boundary energy and leads to a larger driving force for grain coarsening. At high deposition rates and very small original island/grain sizes, the driving force for grain coarsening can be high enough that some grains grow to a huge size. This process is denoted as abnormal grain growth ${ }^{35}$ and manifests itself by the failure to fit the grain-size distribution by a lognormal function [Fig. 3(e)]. This is clearly the case for sample $\mathrm{Al}_{100_{-} 1.0}$ where a wide distribution of grain sizes between less than $50 \mathrm{~nm}$ and $900 \mathrm{~nm}$ is observed. However, the increase of the driving force for grain coarsening is already observed for sample $\mathrm{Al}_{100 \_0.5}$ where the average grain size is already larger than for $\mathrm{Al}_{100 \_0.1}$. Abnormal grain growth may be additionally favored by the formation of large $\mathrm{Al}(111)$ surfaces which have the lowest surface energies of all $\mathrm{Al}$ surfaces ${ }^{23}$ and are, thus, the preferred orientation for large grains. ${ }^{36}$

In the following, we analyze $\mathrm{GBs}$ in the lower $\mathrm{Al}$ layer in more detail for the layers deposited at $100{ }^{\circ} \mathrm{C}$ (cf. Fig. 4) because this deposition temperature yields most homogenous $\mathrm{Al}$ layers in terms of layer thickness. Crystal orientations were determined by comparing 2D Fourier-transform patterns of HRTEM images with calculated diffraction patterns. This procedure allows to determine the orientation of the GB plane and the tilt angles between neighboring grains.

The HRTEM image [Fig. 4(a)] shows a GB with pronounced GB grooving for a sample that was prepared under the same conditions as $\mathrm{Al}_{100 \_0.1}$, but with $\mathrm{UV}$-enhanced oxidation leading to a thicker $\mathrm{AlO}_{\mathrm{x}}$ layer. The (111) lattice planes in the right grain are oriented parallel to the Si substrate while the left grain is not in epitaxial orientation resulting in a GB with low symmetry. The presumably high GB energy leads to strong GB grooving. Figure 4(b) shows a $\mathrm{GB}$ in $\mathrm{Al}_{100 \_0.1}$. The (111) planes of the two adjacent $\mathrm{Al}$ grains are almost parallel to the $\mathrm{Si}(111)$ substrate. Only a slight tilt by about $3^{\circ}$ around the [101] direction is measured between the $\mathrm{Al}$ (111) planes in the two grains leading to a small-angle $(\overline{1} 5 \overline{1}) /(1 \overline{4} 1) \mathrm{GB}$ (we note that we determine the planes in the two adjacent grains that coincide at the GB). The GB is inclined with respect to the $\mathrm{Al} / \mathrm{AlO}_{\mathrm{x}}$ interface. The small-angle $(\overline{1} 5 \overline{1}) /(1 \overline{4} 1) \mathrm{GB}$ does not induce significant GB grooving, but bending of the $\mathrm{Al}$ surface and a change of the crystallographic orientation of the $\mathrm{Al}$ surface at the $\mathrm{Al} / \mathrm{AlO}_{\mathrm{x}}$ interface from $\mathrm{Al}(111)$ to $\mathrm{Al}(101)$ and back to $\mathrm{Al}(111)$. The $\mathrm{AlO}_{\mathrm{x}}$ layer on the $\mathrm{Al}(101)$ surface is $\sim 5 \%$ thicker than on the $\mathrm{Al}(111)$ surface which can be attributed to different oxidation rates on different $\mathrm{Al}$ surfaces. Other grains with higher indexed $\mathrm{Al}$ surfaces at the $\mathrm{Al} / \mathrm{AlO}_{\mathrm{x}}$ interface also show this effect, e.g., a $10 \%-15 \%$ reduced $\mathrm{AlO}_{\mathrm{x}}$ thickness on an $\mathrm{Al}(131)$ surface compared to $\mathrm{Al}(111)$.

Besides the $(\overline{1} 5 \overline{1}) /(1 \overline{4} 1) \mathrm{GB}$, a variety of different GB orientations such as $(\overline{1} \overline{1} \overline{1}) /(1 \overline{1} 1),(101) /(\overline{1} 10)$, and others are observed in $\mathrm{Al}_{100 \_0.1}$. Figure 4 (c) shows a typical $\mathrm{GB}$ in $\mathrm{Al}_{100 \_0.5}$ which is a symmetric tilt boundary of the type $\sum=3 /\{112\}$, i.e., the number of coincidence lattice sites is three and the GB plane is a $\{112\}$ plane in both grains which contains the $\langle 110\rangle$ tilt axis. This twin boundary is a low-energy GB and occurs frequently in facecentered cubic metals. ${ }^{37-39}$ Characteristic features are (a) the (111) planes are parallel in the two neighboring grains, (b) the GB is oriented perpendicular to the $\mathrm{Al} / \mathrm{AlO}_{\mathrm{x}}$ interface, and (c) the GB does not induce bending or grooving. Such a GB can be formed by a $180^{\circ}$ rotation around the [111] direction. $\mathrm{Al}_{100 \_0.5}$ still contains other GBs which are formed if the $\mathrm{Al}(111)$ planes in neighboring grains are tilted against each other. This is the origin of less symmetrical GBs, which are, in general, not perpendicular to the $\mathrm{Al} / \mathrm{AlO}_{\mathrm{x}}$ interface and cause bending or grooving like the GBs shown in Figs. 4(a) and 4(b). In contrast, we observed exclusively $\sum=3 /\{112\}$ twin boundaries in $\mathrm{Al}_{100 \_1.0}$ leading to a highly planar $\mathrm{Al} / \mathrm{AlO}_{\mathrm{x}}$ interface [cf. Fig. 2(e)].

A closer look at the atomic structure of the $\mathrm{Al}$ layer and $\mathrm{Al} / \mathrm{Si}$ interface explains the high content of $\sum=3 /\{112\}$ GBs along $\langle 110\rangle$ directions. It is well known that the $\mathrm{Si}(111) 7 \times 7$ surface contains steps parallel to the $\langle 101\rangle$ directions which separate atomically flat terraces. ${ }^{40,41}$ A $\sum=3 /\{112\}$ GB will be formed if grains on neighboring terraces are rotated by $180^{\circ}$ around the [111] direction and reach a step. HRTEM images of $\mathrm{Al}_{100 \_1.0}$ show $\mathrm{GBs}$ that are solely oriented along $\langle 110\rangle$ directions and thus support the hypothesis presented above. The steps at the $\mathrm{Si}(111)$ surface also lead to a small vertical displacement of the $\mathrm{Al}(111)$ lattice planes across the GB as shown in the Bragg-filtered HRTEM image [Fig. 4(d)] where only the $\mathrm{Al}(111)$ planes are visible. $\sum=3 /\{112\}$ GBs do not show measurable GB grooving due to the low GB energy ${ }^{38}$ and low surface energy of the $\mathrm{Al}(111)$ planes. $^{23}$

It is on first sight surprising that only $\sum=3 /\{112\}$ GBs are formed in $\mathrm{Al}_{100 \_1.0}$ whereas various $\mathrm{GB}$ types occur in all other samples. We attribute this effect to a change of the Al-growth mode. Lognormal grain-size distributions for $\mathrm{Al}_{200 \_0.1}, \mathrm{Al}_{100 \_0.1}$, and $\mathrm{Al}_{100 \_0.5}$ indicate normal grain-growth behavior leading to lateral average grain sizes two to four times of the film thickness ${ }^{34}$ (cf. Table II) while abnormal grain coarsening occurs for $\mathrm{Al}_{100 \_1.0}$. However, more studies are necessary to clarify GB formation in detail. 



FIG. 4. HRTEM images of GBs intersecting the $\mathrm{Al} / \mathrm{AlO}_{\mathrm{x}}$ interface in (a) a sample that was grown under the same conditions as $\mathrm{Al}_{100} 0.1$ apart from the thicker $\mathrm{AlO}_{\mathrm{x}}$ layer where UV-enhanced oxidation was used, (b) $\mathrm{Al}_{100 \_0.1}$, (c) $\mathrm{Al}_{100} 0.5$, and (d) magnified section of the Al-grain boundary in (c) after Bragg filtering for $\mathrm{Al}(111)$ planes. The orientation of the Al grains in (c) is assumed to be rotated by $180^{\circ}$ around the [111] direction. The red lines delineate grain boundaries.

Overall, $\mathrm{Al}_{100 \_1.0}$ with its homogeneous epitaxial lower $\mathrm{Al}$ layer provides the best conditions for the formation of an $\mathrm{AlO}_{\mathrm{x}}$ layer with a constant thickness. Thus, the combined effects of grain properties and influence of GBs are decisive for the optimization of the structural properties of the lower Al layer. The benefit of comparatively large grain sizes (lower GB density) at high substrate temperatures is impaired by corrugated grain surfaces and highenergy GBs, which induce bending and grooving. An $\mathrm{Al}$ layer with optimum properties was fabricated at the lowest deposition temperature $T_{s}=100^{\circ} \mathrm{C}$ and the highest deposition rate $r=1.0 \mathrm{~nm} / \mathrm{s}$. We could not further reduce $T_{s}$ due to the lack of active substrate cooling in our deposition system, which increases the cooling time to up to a few hours after the high-temperature substrate treatment. Within this time interval, the Si surface can be reoxidized by residual oxygen, resulting in a thin $\mathrm{SiO}_{\mathrm{x}}$ layer which is detrimental to achieving epitaxial $\mathrm{Al}$ growth. For constant low $T_{s}$, increasing deposition rates (which are limited to $1.0 \mathrm{~nm} / \mathrm{s}$ in our deposition system) lead to larger average grain sizes by anomalous grain growth. Increasing deposition rates also favor preferential formation of low-energy $\sum=3 /\{112\}$ GBs which do not induce grooving or bending at the $\mathrm{Al} / \mathrm{AlO}_{\mathrm{x}}$ interface.

\section{Properties of $\mathrm{AlO}_{\mathrm{x}}$ and the upper $\mathrm{Al}$ layer}

After $\mathrm{Al}$ deposition, the surface was oxidized by static oxidation with pure $\mathrm{O}_{2}$ to form an amorphous $\mathrm{AlO}_{\mathrm{x}}$-tunnel barrier with a thickness of $1.5-2.0 \mathrm{~nm}$. Although the oxidation conditions (oxidation times, oxidation temperature, and $\mathrm{O}_{2}$-partial pressures) were varied to obtain $\mathrm{AlO}_{\mathrm{x}}$ with different properties (to be presented separately), we will show in the following that the homogeneity of the $\mathrm{AlO}_{\mathrm{x}}$ layer depends to a large degree on the surface roughness of the lower $\mathrm{Al}$ layer. We note that plasma-enhanced oxidation was applied for $\mathrm{Al}_{100 \_1.0}$ to increase the oxygen content of the $\mathrm{AlO}_{\mathrm{x}}$ layer. This also leads to an increased $\mathrm{AlO}_{\mathrm{x}}$-layer thickness, making this layer unsuitable for the fabrication of Josephson junctions, but it provides useful information concerning the crystallographic orientation of the upper $\mathrm{Al}$ layer. Also, the different $\mathrm{AlO}_{\mathrm{x}}$ properties of $\mathrm{Al}_{100 \_1.0}$ do not affect the conclusions regarding the optimization of the $\mathrm{Al}$ deposition in Sec. III B.

Average values and standard deviations of the $\mathrm{AlO}_{\mathrm{x}}$-layer thickness were measured for all samples according to the procedure described in Sec. II and are listed in Table II. All layers have overall thicknesses between $1.59 \mathrm{~nm}$ and $1.73 \mathrm{~nm}$ apart from $4.88 \mathrm{~nm}$ for 
$\mathrm{Al}_{100 \_1.0}$ where plasma-enhanced oxidation was applied. The thickness variation of the $\mathrm{AlO}_{\mathrm{x}}$ layers $\Delta t$ improves with decreasing $T_{s}$ and increasing $r$ from $0.29 \mathrm{~nm}$ for $\mathrm{Al}_{300 \_0.1}$ to $0.11 \mathrm{~nm}$ for $\mathrm{Al}_{100 \_0.5}$ and shows the same trend as the thickness variation of the lower Al layer (cf. Table II). On first sight, the $\mathrm{AlO}_{\mathrm{x}}$-layer thickness of $\mathrm{Al}_{100 \_1.0}$ with a slightly larger $\Delta t$ of $0.17 \mathrm{~nm}$ does not seem to follow the trend, but the overall thickness of the $\mathrm{AlO}_{\mathrm{x}}$ layer is by a factor of three larger due to the application of a plasma-enhanced oxidation process in this particular case. Although the absolute $\Delta t$ value of $\mathrm{Al}_{100 \_1.0}$ increases slightly with respect to $\mathrm{Al}_{100 \_0.5}$, the percentage of the thickness variation is reduced from $6.9 \%$ for $\mathrm{Al}_{100 \_0.5}$ to $3.5 \%$ for $\mathrm{Al}_{100 \_1.0}$. The reduction of $\Delta t$ can be, in general, attributed to the decrease of the content of high-energy GBs (and higher content of low-energy $\sum=3 /\{112\}$ GBs) which reduces $\mathrm{GB}$ grooving and leads to a smoother $\mathrm{Al} / \mathrm{AlO}_{\mathrm{x}}$ interface.

The small absolute $\Delta t$ increase in $\mathrm{Al}_{100 \_1.0}$ can be mainly attributed to the upper $\mathrm{Al} / \mathrm{AlO}_{\mathrm{x}}$ interface, which is more corrugated due to random grain orientations in the upper $\mathrm{Al}$ layer on the comparatively thick $\mathrm{AlO}_{\mathrm{x}}$ layer [cf. Fig. 5(a)]. In contrast, an abrupt upper $\mathrm{Al} / \mathrm{AlO}_{\mathrm{x}}$ interface is observed in $\mathrm{Al}_{100} 0.5$ with an epitaxial Al-grain orientation in the upper layer that is preserved across the thin $\mathrm{AlO}_{\mathrm{x}}$ layer [cf. Fig. 5(b)]. The HRTEM images in Fig. 5 also demonstrate that, besides thickness variations due to GB grooving [cf. Fig. 4(a)] or Al surfaces with different crystallographic orientation [cf. Fig. 4(b)], thickness variations are caused by atomic steps at $\mathrm{Al} / \mathrm{AlO}_{\mathrm{x}}$ interfaces even in epitaxial $\mathrm{Al}$ layers. A HRTEM image of $\mathrm{Al}_{100 \_0.5}$ [Fig. 5(b)] shows such steps at the lower and upper $\mathrm{Al} / \mathrm{AlO}_{\mathrm{x}}$ interface. The upper $\mathrm{Al}$ layer is tilted by about $0.5^{\circ}$ from the [111] direction which leads to an increase of atomic steps. The thickness of the $\mathrm{AlO}_{\mathrm{x}}$ layer will inevitably vary if the steps do not occur at the same lateral position or the step density is not identical at the lower and upper $\mathrm{Al} / \mathrm{AlO}_{\mathrm{x}}$ interfaces.

These observations confirm once more that thickness variations of the lower $\mathrm{Al}$ layer correlate with thickness variations of the $\mathrm{AlO}_{\mathrm{x}}$ layer and emphasize the influence of structural properties of the lower $\mathrm{Al}$ layer on the $\mathrm{AlO}_{\mathrm{x}}$ layer. The HRTEM images in Fig. 5 also visualize that the crystallographic orientation of grains in the upper Al layer also influences the thickness homogeneity of the $\mathrm{AlO}_{\mathrm{x}}$ layer. The thickness homogeneity of the $\mathrm{AlO}_{\mathrm{x}}$ layer can be optimized if the crystallographic orientation of the lower and upper layers is identical. We note that the lower and upper $\mathrm{Al}$ layers were always deposited with the same deposition rate and nominally the same $T_{s}$ but deviations of about $\pm 20^{\circ} \mathrm{C}$ may have occurred for the upper layers depending on the oxidation temperature.

It is, in general, expected that grain orientations in the lower and upper Al layers are different due to the presence of the amorphous $\mathrm{AlO}_{\mathrm{x}}$ layer in between. This expectation is confirmed for $\mathrm{Al}_{300 \_0.1}, \mathrm{Al}_{200 \_0.1}$, and $\mathrm{Al}_{100 \_0.1}$ where grains in the upper $\mathrm{Al}$ layer show different Bragg contrast than grains in the lower $\mathrm{Al}$ layer [cf. Figs. 2(a)-2(c)]. However, the upper $\mathrm{Al}$ layer in $\mathrm{Al}_{100 \_0.1}$ also contains some grains that grow with $\mathrm{Al}(111)$ lattice planes parallel to the lower $\mathrm{Al}$ layer, i.e., the information on the crystallographic orientation is transferred across the amorphous $\mathrm{AlO}_{\mathrm{x}}$ layer. Other $\mathrm{Al}$ grains in the upper layer are often only slightly misoriented with respect to $\mathrm{Al}(111)$. For $\mathrm{Al}_{100 \_0.5}$, the fraction of well aligned grains with $\mathrm{Al}(111)$ lattice planes parallel to the $\mathrm{AlO}_{\mathrm{x}}$ layer increases and only small orientation deviations between upper and lower $\mathrm{Al}$ grains are typically observed [cf. Figs. 4(c) and 5(b)]. More random grain orientations are observed on a thicker $\mathrm{AlO}_{\mathrm{x}}$ layer as for $\mathrm{Al}_{100 \_1.0}$ with an $\mathrm{AlO}_{\mathrm{x}}$ thickness of $4.88 \mathrm{~nm}$ [cf. Fig. 5(a)]. However, it is not only the $\mathrm{AlO}_{\mathrm{x}}$-layer thickness that determines the transfer of the orientation information, because the average $\mathrm{AlO}_{\mathrm{x}}$-layer thickness is almost identical for $\mathrm{Al}_{300 \_0.1}, \mathrm{Al}_{200 \_0.1}, \mathrm{Al}_{100 \_0.1}$, and $\mathrm{Al}_{100 \_0.5}$ (cf. Table II). The phenomenon is only found in $\mathrm{Al}_{100 \_0.5}$ and to a lesser degree in $\mathrm{Al}_{100} 0.1$ where the Al-deposition conditions favor epitaxial growth. For the other samples, the deposition parameters lead to a larger variation of grain orientations in the lower Al layer despite a clean $\mathrm{Si}(111)$ surface, and it is reasonable that this behavior pertais in the upper Al layer.

The transfer of crystallographic orientation from the lower to the upper Al layer was also found in molecular dynamics simulations by DuBois et al., ${ }^{42}$ where $\mathrm{Al}$ grown on a thin amorphous $\mathrm{AlO}_{\mathrm{x}}$ layer $(1.2 \mathrm{~nm}$ thick) tends to pick up the orientation of the lower Al layer. A possible explanation could be pinholes in the



FIG. 5. HRTEM images of $A l / A I O_{x}$ interfaces in (a) $\mathrm{Al}_{100} 1.0$ and (b) $\mathrm{Al}_{100}{ }_{0.5}$. Atomic steps at the $\mathrm{Al} / \mathrm{AlO}_{\mathrm{x}}$ interfaces are marked by white arrows. 
$\mathrm{AlO}_{\mathrm{x}}$ layer which form during the first stage of the oxidation. ${ }^{43}$ However, this should only happen for ultrathin $\mathrm{AlO}_{\mathrm{x}}$ layers (less than $0.6-0.8 \mathrm{~nm}$ ), whereas thicker layers should form a continuous layer. Electrical measurements on JJs also showed a reduced tunneling resistance and increased leakage currents for a critical $\mathrm{AlO}_{\mathrm{x}}$-layer thickness below $1 \mathrm{~nm} .^{44,45}$ According to these observations, we can expect continuous $\mathrm{AlO}_{\mathrm{x}}$ layers in our samples because the critical thickness for pinhole formation is exceeded and HRTEM images do not indicate pinhole formation. We speculate that the periodic potential of the $\mathrm{Al}(111)$ surface across a thin $\mathrm{AlO}_{\mathrm{x}}$ layer can still be strong enough to initiate $\mathrm{Al}$ growth with the same orientation. Thus, despite optimum $\mathrm{Al}$-growth conditions, $\mathrm{Al}_{100 \_1.0}$ shows more random grain orientation than $\mathrm{Al}_{100 \_0.5}$ due to the increased $\mathrm{AlO}_{\mathrm{x}}$-layer thickness of $4.88 \mathrm{~nm}$. In summary, epitaxial growth conditions (low temperatures and high deposition rates) combined with a thin $\mathrm{AlO}_{\mathrm{x}}$ layer with a thickness below $2 \mathrm{~nm}$ will lead to a well oriented upper $\mathrm{Al}$ layer and an $\mathrm{AlO}_{\mathrm{x}}$ layer with minimal thickness variations, but the origin and conditions of transfer of information on the crystallographic orientation across thin amorphous $\mathrm{AlO}_{\mathrm{x}}$ layers has to be further investigated.

\section{CONCLUSIONS}

$\mathrm{Al} / \mathrm{AlO}_{\mathrm{x}} / \mathrm{Al}$-layer systems for applications in Josephson junctions were deposited on $\mathrm{Si}(111)$ substrates in a standard highvacuum electron-beam deposition system in this work. It is demonstrated that optimization of the growth of the lower Al layer leads to epitaxial lower Al layers with the desired homogenization of the $\mathrm{AlO}_{\mathrm{x}}$ layer thickness and, correspondingly, an optimization of the properties of the whole $\mathrm{Al} / \mathrm{AlO}_{\mathrm{x}} / \mathrm{Al}$-layer system. The following conclusions can be drawn from the correlation of deposition parameters and the structural properties of the $\mathrm{Al} / \mathrm{AlO}_{\mathrm{x}} / \mathrm{Al}$-layer systems:

- HF-cleaning and high-temperature treatment (in our case $700{ }^{\circ} \mathrm{C}$ for $20 \mathrm{~min}$ ) are mandatory to achieve epitaxial growth of $\mathrm{Al}(111)$ on $\mathrm{Si}(111)$.

- Epitaxial growth of the lower Al layer on Si(111) was achieved for low substrate temperatures and high deposition rates $\left(100^{\circ} \mathrm{C}\right.$ and $1 \mathrm{~nm} / \mathrm{s}$ in our case). Under these conditions, grains with large lateral sizes and planar surfaces are formed due to abnormal grain growth. In addition, grooving and bending of the $\mathrm{Al} / \mathrm{AlO}_{\mathrm{x}}$ interface and corresponding $\mathrm{AlO}_{\mathrm{x}}$ thickness variations are avoided because only $\sum=3 /\{112\}$ symmetrical twin boundaries occur in the lower Al layer. Elimination of other GB types, which are formed at higher substrate temperatures and lower deposition rates, improves the planarity of the $\mathrm{Al} / \mathrm{AlO}_{\mathrm{x}}$ interface and homogenizes the $\mathrm{AlO}_{\mathrm{x}}$-layer thickness. It is also favorable that, under these conditions, the information of the crystallographic orientation of the lower Al layer is transferred across $\mathrm{AlO}_{\mathrm{x}}$ layers with a thickness below $2 \mathrm{~nm}$.

Further reduction of the substrate temperature during $\mathrm{Al}$ deposition may be beneficial because a transition from a growth mode, which is dominated by grain nucleation and grain growth, to a twodimensional layer-by-layer growth may occur. This requires active substrate cooling to keep the time between high-temperature Si-substrate treatment and start of the $\mathrm{Al}$ deposition as short as possible to avoid reoxidation and contamination of the Si substrate. We also point out that our study may pave the way for growing crystalline $\mathrm{Al}_{2} \mathrm{O}_{3}$-tunnel barriers on epitaxial $\mathrm{Al}(111)$, which has been achieved up to now only in an UHV system and which may be beneficial for reducing noise in Josephson junction-based superconducting devices.

\section{ACKNOWLEDGMENTS}

We thank Dr. Silvia Diewald (CFN Nanostructure Service Laboratory, Karlsruhe Institute of Technology) for carrying out the HF-dip and Dr. Johannes Rotzinger (Physikalisches Institut, Karlsruhe Institute of Technology) for enlightening discussions.

\section{REFERENCES}

${ }^{\mathbf{1}}$ M. H. Devoret and R. J. Schoelkopf, "Superconducting circuits for quantum information: An outlook,” Science 339(6124), 1169-1174 (2013).

${ }^{\mathbf{2}}$ Y.-F. Chen et al., "Microwave photon counter based on Josephson junctions," Phys. Rev. Lett. 107(21), 217401 (2011).

${ }^{3}$ P. L. Richards and T.-M. Shen, "Superconductive devices for millimeter wave detection, mixing, and amplification," IEEE Trans. Electron. Devices 27(10), 1909-1920 (1980).

${ }^{4}$ T. J. Harvey et al., "Current noise of a superconducting single-electron transistor coupled to a resonator," Phys. Rev. B 78(2), 367 (2008).

${ }^{5}$ J. Clarke and A. I. Braginski, The SQUID Handbook-Vol. 1 Fundamentals and Technology of SQUIDS and SQUID Systems (Wiley-VCH, Cambridge, 2002).

${ }^{\mathbf{6}} \mathrm{R}$. Kleiner et al., "Superconducting quantum interference devices: State of the art and applications," Proc. IEEE 92(10), 1534-1548 (2004).

${ }^{7}$ L. J. Zeng et al., "Direct observation of the thickness distribution of ultra thin $\mathrm{AlO}_{\mathrm{x}}$ barriers in $\mathrm{Al} / \mathrm{AlO}_{\mathrm{x}} / \mathrm{Al}$ Josephson junctions," J. Phys. D Appl. Phys. 48(39), 395308 (2015).

${ }^{8}$ S. Nik et al., "Correlation between $\mathrm{Al}$ grain size, grain boundary grooves and local variations in oxide barrier thickness of $\mathrm{Al} / \mathrm{AlO}_{\mathrm{x}} / \mathrm{Al}$ tunnel junctions by transmission electron microscopy," SpringerPlus 5(1), 1067 (2016).

${ }^{9}$ S. Fritz et al., "Correlating the nanostructure of Al-oxide with deposition conditions and dielectric contributions of two-level systems in perspective of superconducting quantum circuits," Sci. Rep. 8(1), 7956 (2018).

${ }^{10}$ Y. Miura et al., "Single-crystal Al growth on $\mathrm{Si}(111)$ by low-temperature molecular beam epitaxy,” Appl. Phys. Lett. 62(15), 1751-1753 (1993).

${ }^{11}$ M.-A. Hasan et al., "Epitaxial growth of $\mathrm{Al}$ on $\mathrm{Si}(100)$ and $\mathrm{Si}(111)$ by evaporation in UHV," Vacuum 41(4-6), 1121-1123 (1990).

${ }^{12}$ E. A. Khramtsova et al., "Growth of extra-thin ordered aluminum films on $\mathrm{Si}$ (111) surface,” Appl. Surf. Sci. 82-83, 576-582 (1994).

${ }^{13}$ F.-F. Su et al., "Superconducting phase qubits with shadow-evaporated Josephson junctions," Chin. Phys. B 26(6), 60308 (2017).

${ }^{14} \mathrm{Y}$.-L. Wu et al., "Fabrication of $\mathrm{Al} / \mathrm{AlO}_{\mathrm{x}} / \mathrm{Al}$ Josephson junctions and superconducting quantum circuits by shadow evaporation and a dynamic oxidation process," Chin. Phys. B 22(6), 60309 (2013).

${ }^{15} \mathrm{D}$. Diesing et al., "Aluminium oxide tunnel junctions: Influence of preparation technique, sample geometry and oxide thickness," Thin Solid Films 342(1-2), 282-290 (1999).

${ }^{16} \mathrm{~J}$. Burnett et al., "Noise and loss of superconducting aluminium resonators at single photon energies," J. Phys. Conf. Ser. 969, 12131 (2018).

17. K. Julin et al., "Reduction of low-frequency $1 / \mathrm{f}$ noise in $\mathrm{Al}-\mathrm{AlOx}-\mathrm{Al}$ tunnel junctions by thermal annealing," Appl. Phys. Lett. 97(15), 152501 (2010).

${ }^{18} \mathrm{~A}$. Inoue et al., "Nb/ $\mathrm{AlO}_{\mathrm{x}} / \mathrm{Nb}$ Josephson tunnel junctions using electron beam evaporation,” Jpn. J. Appl. Phys. 27(Part 1, No. 7), 1234-1239 (1988).

${ }^{19}$ A. Megrant et al., "Planar superconducting resonators with internal quality factors above one million,” Appl. Phys. Lett. 100(11), 113510 (2012). 
${ }^{20} \mathrm{D}$. Ali and C. J. Richardson, "Reflection high-energy electron diffraction evaluation of thermal deoxidation of chemically cleaned $\mathrm{Si}$, SiGe, and Ge layers for solid-source molecular beam epitaxy," J. Vac. Sci. Technol. A 30(6), 61405 (2012).

${ }^{21} \mathrm{P}$. Allongue et al., "The preparation of flat $\mathrm{H}-\mathrm{Si}(111)$ surfaces in $40 \% \mathrm{NH}_{4} \mathrm{~F}$ revisited," Electrochim. Acta 45(28), 4591-4598 (2000).

${ }^{\mathbf{2 2}} \mathrm{C}$. T. Earnest $e t$ al., "Substrate surface engineering for high-quality silicon/aluminum superconducting resonators," Supercond. Sci. Technol. 31(12), 125013 (2018).

${ }^{23}$ N. E. Singh-Miller and N. Marzari, "Surface energies, work functions, and surface relaxations of low-index metallic surfaces from first principles," Phys. Rev. B 80(23), 659 (2009).

${ }^{24} \mathrm{~F}$. Reichel et al., "Amorphous versus crystalline state for ultrathin $\mathrm{Al}_{2} ; \mathrm{O}_{3}$ overgrowths on $\mathrm{Al}$ substrates," J. Appl. Phys. 103(9), 93515 (2008).

${ }^{25} \mathrm{~L}$. P. H. Jeurgens et al., "Thermodynamic stability of amorphous oxide films on metals: Application to aluminum oxide films on aluminum substrates," Phys. Rev. B 62(7), 4707-4719 (2000).

${ }^{\mathbf{2 6}} \mathrm{B}$. M. McSkimming et al., "Metamorphic growth of relaxed single crystalline aluminum on silicon (111)," J. Vac. Sci. Technol. A 35(2), 21401 (2017).

${ }^{27} \mathrm{Y}$. Horio, "Different growth modes of $\mathrm{Al}$ on $\mathrm{Si}(111) 7 \times 7$ and $\mathrm{Si}$ (111) $\sqrt{3} \times \sqrt{ } 3-A l$ surfaces," Jpn. J. Appl. Phys. 38, 4881-4886 (1999).

${ }^{28}$ I. Yamada et al., "Epitaxial growth of $\mathrm{Al}$ on $\mathrm{Si}(111)$ and $\mathrm{Si}(100)$ by ionized-cluster beam," J. Appl. Phys. 56(10), 2746-2750 (1984).

${ }^{29} \mathrm{G}$. S. Higashi et al., "Comparison of $\mathrm{Si}(111)$ surfaces prepared using aqueous solutions of $\mathrm{NH}_{4} \mathrm{~F}$ versus HF," Appl. Phys. Lett. 58(15), 1656-1658 (1991).

${ }^{30} \mathrm{~A}$. Strecker et al., "Specimen preparation for transmission electron microscopy (TEM)-reliable method for cross sections and brittle materials," Prakt. Metallogr. 30(10), 482-495 (1993).

${ }^{31} \mathrm{P}$. Stadelmann, "Image analysis and simulation software in transmission electron microscopy," Microsc. Microanal. 9(Suppl. 3), 60-61 (2003).
${ }^{32}$ J. E. Palmer et al., "Grain growth and grain size distributions in thin germanium films," J. Appl. Phys. 62(6), 2492-2497 (1987).

${ }^{33} \mathrm{C}$. V. Thompson and R. Carel, "Stress and grain growth in thin films," J. Mech. Phys. Solids 44(5), 657-673 (1996).

${ }^{34}$ C. Thompson, "Grain growth in thin films," Annu. Rev. Mater. Res. 20(1), 245-268 (1990).

${ }^{35} \mathrm{H}$. J. Frost et al., "Simulation of thin film grain structures-II. Abnormal grain growth,” Acta Metall. Mater. 40(4), 779-793 (1992).

${ }^{36} \mathrm{H}$. P. Longworth and C. V. Thompson, "Abnormal grain growth in aluminum alloy thin films," J. Appl. Phys. 69(7), 3929-3940 (1991).

${ }^{37}$ J. D. Rittner and D. N. Seidman, "〈 $\langle 110\rangle$ symmetric tilt grain-boundary structures in fcc metals with low stacking-fault energies," Phys. Rev. B 54(10), 6999-7015 (1996).

${ }^{38} \mathrm{M}$. A. Tschopp et al., "Symmetric and asymmetric tilt grain boundary structure and energy in $\mathrm{Cu}$ and $\mathrm{Al}$ (and transferability to other fcc metals)," Integrating Mater. 4(1), 1117 (2015).

${ }^{39}$ J. M. Pénisson et al., "HREM study of a $\sum=3\{112\}$ twin boundary in aluminium," Philos. Mag. Lett. 64(5), 277-283 (1991).

${ }^{40}$ R. S. Becker et al., "Tunneling images of atomic steps on the $\mathrm{Si}(111) 7 \times 7$ surface,” Phys. Rev. Lett. 55(19), 2028-2031 (1985).

${ }^{41} \mathrm{H}$. Tochihara et al., "Structure and restructuring of the atomic steps on $\mathrm{Si}$ (111)7 × 7,” Phys. Rev. B 45(19), 11332-11335 (1992).

${ }^{42} \mathrm{~T}$. C. DuBois et al., "Constructing ab initio models of ultra-thin $\mathrm{Al} / \mathrm{AlO} \mathrm{X}_{\mathrm{x}} / \mathrm{Al}$ barriers," Mol. Simul. 42(6-7), 542-548 (2015).

${ }^{43} \mathrm{X}$. W. Zhou et al., "Transient hole formation during the growth of thin metal oxide layers," Comput. Mater. Sci. 39(4), 794-802 (2007).

${ }^{44} \mathrm{D}$. Song et al., "Proper oxidation for spin-dependent tunnel junctions," J. Appl. Phys. 87(9), 5197-5199 (2000).

${ }^{45} \mathrm{~J}$. H. Lee et al., "Failure of exchange-biased low resistance magnetic tunneling junctions upon thermal treatment," J. Appl. Phys. 91(1), 217 (2002). 